\title{
CUTTON BUD SEBAGAI ALAT PENDETEKSI BORAKS PADA DAGING AYAM POTONG YANG DIPERJUALBELIKAN DI PASAR PA'BAENG-BAENG KOTA MAKASSAR
}

\author{
Nur Qadri Rasyid ${ }^{1)}$, Anita $^{1)}$, Eva Trianingsih ${ }^{1)}$ \\ ${ }^{1)}$ Prodi D3 Teknologi Laboratorium Medis Politeknik Kesehatan Muhammadiyah Makassar \\ Email: nqadrir@gmail.com
}

\begin{abstract}
Abstrak
Keracunan makanan salah satunya disebabkan karena adanya cemaran kimia dalam makanan tersebut, seperti penambahan boraks untuk memperpanjang masa simpan produk. Data Badan Pengawas Obat dan Makanan (BPOM) menunjukkan bahwa sepanjang tahun 2012, Insiden keracunan akibat mengkonsumsi makanan menduduki posisi paling tinggi, yaitu 66,7\%, dibandingkan dengan keracunan akibat penyebab lain. Dalam data tersebut, diketahui 2,93\% sampel makanan jajanan pada anak sekolah mengandung boraks. Akumulasi boraks di dalam tubuh dapat berdampak negatif bagi kesehatan. Boraks merupakan Kristal lunak yang mengandung unsur-unsur boron, bewarna dan larut dalam air, tidak berbau, stabil pada suhu tinggi serta tekanan normal. Boraks digunakan sebagai pengawet pada ayam potong untuk memperpanjang masa penyimpanan pada ayam potong. Namun pemakaian boraks disalahgunakan untuk dijadikan sebagai bahan pengawet pada makanan karena memiliki sifat sebagai antiseptik, pengontrol kecoa, bahan solder dan pembersih alat dapur. Penelitian ini bertujuan untuk mengidentifikasi boraks pada daging ayam potong dengan menggunakan Cutton bud yang diperjualbelikan pada pasar pa'baeng-baeng Makassar. Berdasarkan hasil pemeriksaan yang dilakukan dengan menggunakan 20 sampel paha ayam potong menunjukan bahwa 1 sampel positif mengandung boraks. Hasil ini ditunjukan dengan adanya perubahan warna pada kapas cutton bud dari kuning menjadi bewarna merah ini menandakan bahwa boraks ditambahkan pada sebagian kecil pedagang ayam potong dipasar pa'baeng-baeng Makassar.
\end{abstract}

Kata Kunci: Cutton Bud, Boraks, Ayam Potong

\section{PENDAHULUAN}

Perhatian terhadap keamanan pangan merupakan suatu hal yang dapat berdampak pada kesehatan, baik bagi anak-anak maupun orang dewasa. Menurut data dari Badan Pengawas Obat dan Makanan (BPOM), sepanjang tahun 2012, insiden keracunan akibat mengonsumsi makanan menduduki posisi paling tinggi, yaitu $66,7 \%$, dibandingkan dengan keracunan akibat penyebab lain, misalnya obat, kosmetika, dan lain-lain. Salah satu penyebab keracunan makanan adalah adanya cemaran kimia dalam makanan tersebut. Kasus cemaran kimia yang masih sering ditemui adalah adanya kandungan bahan-bahan berbahaya seperti formalin, boraks, dan pewarna tekstil dalam makanan. Bahan-bahan tersebut tidak seharusnya terdapat dalam makanan karena dapat membahayakan kesehatan, namun dengan alasan untuk menekan biaya produksi dan memperpanjang masa simpan, banyak produsen yang masih menggunakan bahanbahan tersebut. Jenis makanan yang seringkali mengandung bahan berbahaya tersebut salah satunya adalah golongan bahan pangan daging utamanya daging ayam yang diperjual belikan di pasar tradisional.

Penggunaan bahan tambahan pangan diatur dalam peraturan pemerintah nomor 
28 tahun 2004 pasal 9, yakni setiap orang yang memproduksi makanan yang diedarkan dilarang menggunakan bahan apapun sebagai bahan tambahan pangan, tetapi belum di ketahui dampaknya bagi kesehatan manusia, wajib di periksa keamanannya terlebih dahulu, dan dapat digunakan dalam kegiatan atau proses produksi makanan untuk diedarkan, setelah memperoleh persetujuan BPOM (Cahyadi, 2009).

Boraks merupakan senyawa kimia berbahaya untuk pangan dengan nama kimia Natrium Tetraborat $\left(\mathrm{Na}_{2} \mathrm{~B}_{4} \mathrm{O}_{7} \cdot 10 \mathrm{H}_{2} \mathrm{O}\right)$. Bisa didapatkan dalam bentuk cair atau padat (Natrium Hidroksida atau Asam borat $\left(\mathrm{H}_{3} \mathrm{BO}_{3}\right)$. Baik boraks maupun asam boraks memiliki sifat antiseptik dan biasa diguanakan oleh industri farmasi sebagai ramuan obat, misalnya dalam salep, bedak, larutan kompreks, obat oles mulut, dan obat pencuci mata. Boraks juga digunakan sebagai bahan solder, bahan pembersih, pengawet kayu, dan anti septik kayu.

Pemakaian boraks pada makanan dapat menyebabkan keracunan pada tubuh manusia dengan gejala, susah menelan, mual, sakit perut yang akut, disertai muntah-muntah, mencret darah, timbulnya depresi, susunan syaraf atau gangguan peredaran darah (Bahri, S, 2008).

Kesalahan fatal yang dilakukan oleh para produsen makanan adalah menggunakan boraks sebagai bahan pengawet makanan. Hal ini di sebabkan karena kurangnya informasi tentang boraks dan bahayanya. Tingkat kesadaran kesehatan masyarakat yang masih rendah, harga boraks yang sangat murah, dan kemudahannya didapat, selain itu boraks efektif digunakan sebagai pengawet. Penggunaan hanya dalam jumlah sedikit. Sebaliknya, konsumen mau menerima bahan makanan yang mengandung boraks Karena ketidaktahuan mereka dan kecenderungan untuk mendapatkan makanan yang murah dan awet. Selain itu, konsumen belum bisa membedakan produk yang di awetkan dengan pengawet dari produk yang diawetkan oleh boraks (Murti, Tridjoko, 2014).

Akhir-akhir ini boraks sering digunakan untuk mengawetkan makanan seperti tahu, mi basah, ikan dan daging ayam. Para pedagang yang tidak bertanggung jawab sengaja memilih boraks karena harganya yang lebih murah jika dibanding dengan pengawet makanan yang diperbolehkan, seperti asam sorban atau natrium benzoat. Selain murah, boraks juga lebih irit, mudah digunakan karena berbentuk larutan serta mudah didapatkan di toko-toko kimia.

\section{METODE PENELITIAN}

\section{Alat dan Bahan}

Alat yang digunakan dalam penelitian ini adalah Cutton bud, pisau, gelas kimia, pipet tetes, gelas ukur. Bahan penelitian yang digunakan adalah sampel (daging ayam potong yang diduga mengandung boraks), kunyit, dan boraks.

\section{Prosedur Kerja}

Memasukan ujung cutton bud kedalam rimpang kunyit yang telah diiris membujur. Diamkan selama 20 detik hingga kapas cutton bud telah bewarna kuning. Sampel ayam potong yang telah diambil pada bagian paha diiris melintang kemudian tusukan cutton bud tersebut pada 
sampel ayam potong selama 10 detik, jika sampel ayam potong mengandung boraks maka akan terjadi perubahan warna cutton bud dari kuning menjadi warna merah, lalu bandingkan dengan control positif dan negatif.

\section{Interpretasi Hasil}

Jika terjadi perubahan warna merah terang maka positif (+) mengandung boraks sedangkan jika tidak terjadi perubahan warna maka menunjukan negatif (-) tidak mengandung boraks.

\section{HASIL PENELITIAN}

Boraks merupakan garam natrium yang banyak digunakan diberbagai industri non pangan, khususnya industri, gelas, pengawet kayu, dan keramik. Namun saat ini banyak pula digunakan oleh para pembuat dan penjual bakso, mie ayam, dan berbagai jenis makanan lainnya. Penambahan ini bertujuan agar produk makanan tersebut memiliki sifat tekstur lebih kenyal sehingga menambah sensasi kenikmatan ketika disantap dan tidak mudah rusak, Edisi Revisi Permenkes RI Nomor. 033 tahun 2012 tentang bahan tambahan pada pangan dan bahayanya melarang penggunaan boraks pada makanan, Namun, penggunaan boraks masih banyak digunakan oleh pedagang yang tidak bertanggung jawab. Sehingga dibutuhkan penelitian untuk mengetahui penggunaan boraks pada bahan pangan yang beredar dipasaran.

Penelitian ini dilakukan di laboratorium toksikologi Poltekkes Muhammadiyah Makassar. Subjek dalam penelitian ini yaitu identifikasi Boraks pada daging ayam potong dengan menggunakan cutton bud yang diperjualbelikan pada pasar
Pa'baeng-baeng Makassar, dengan jumlah sampel sebanyak 20 sampel paha ayam potong. Hasil penelitian yang diperoleh disajikan dalam bentuk tabel sebagai berikut:

Tabel 1.Hasil identifikasi Boraks Pada Daging Ayam Potong dengan menggunakan Cutton bud yang diperjualbelikan pada Pasar Pa'baeng-baeng Makassar.

\begin{tabular}{|c|c|c|}
\hline $\begin{array}{c}\text { Kode } \\
\text { Sampel }\end{array}$ & $\begin{array}{c}\text { Uji } \\
\text { Kualitatif }\end{array}$ & Keterangan \\
\hline Kontrol & Merah & + \\
\hline Positif & & \\
\hline Kontrol & Kuning & - \\
\hline Negatif & & \\
\hline A & Kuning & - \\
\hline $\mathrm{B}$ & Merah & + \\
\hline $\mathrm{C}$ & Kuning & - \\
\hline $\mathrm{D}$ & Kuning & - \\
\hline $\mathrm{E}$ & Kuning & - \\
\hline $\mathrm{F}$ & Kuning & - \\
\hline G & Kuning & - \\
\hline $\mathrm{H}$ & Kuning & - \\
\hline I & Kuning & - \\
\hline $\mathbf{J}$ & Kuning & - \\
\hline $\mathrm{K}$ & Kuning & - \\
\hline $\mathrm{L}$ & Kuning & - \\
\hline M & Kuning & - \\
\hline $\mathrm{N}$ & Kuning & - \\
\hline $\mathrm{O}$ & Kuning & - \\
\hline $\mathrm{P}$ & Kuning & - \\
\hline Q & Kuning & - \\
\hline $\mathrm{R}$ & Kuning & - \\
\hline S & Kuning & - \\
\hline $\mathrm{T}$ & Kuning & - \\
\hline
\end{tabular}


Pada penelitian ini sampel diambil berdasarkan ciri dan kriteria misalnya tidak mudah dihinggapi lalat dan dagingnya masih kelihatan segar walaupun disimpan dalam jangka waktu yang lama. Diambil sebanyak 20 sampel paha ayam potong pada 4 orang pedagang ayam potong, yang masing-masing pedagang diambil 5 sampel paha ayam potong. Berdasarkan tabel 1 hasil pemeriksaan yang dilakukan dengan menggunakan 20 sampel paha ayam potong hanya 1 sampel positif mengandung boraks hal ini ditunjukan dengan adanya perubahan warna pada kapas cutton bud dari kuning menjadi bewarna merah. Perubahan warna ini dikarenakan pada kunyit mengandung kurkumin yang dapat mengidentifikasi boraks. sampel negatif Karena pada saat cutton bud yang sudah dicelupkan dengan kunyit bijis kemudian dimasukan kedalam sayatan paha ayam tidak berbentuk asam borat hal ini ditandai dengan tidak adanya perubahan warna pada cutton bud yang menjadi indikator adanya boraks didalam sampel yang diteliti, seperti reaksi berikut:

$\mathrm{Na}_{2} \mathrm{~B}_{4} \mathrm{O}_{7} \cdot 10 \mathrm{H}_{2} \mathrm{O}+2 \mathrm{HCl} \rightarrow 2 \mathrm{NaCl}+$ $4 \mathrm{H}_{3} \mathrm{BO}_{3}+\mathrm{H}_{2} \mathrm{O}$

$\mathrm{C}_{21} \mathrm{H}_{20} \mathrm{O}_{6}+\mathrm{H}_{3} \mathrm{BO}_{3} \rightarrow$ warna merah / Rososiania.

Penggunaan boraks pada bahan pangan berakibat buruk terhadap kesehatan karena akan diserap dalam tubuh konsumen secara kumulatif. Selain melalui saluran pencernaan, boraks juga bisa diserap melalui kulit. Boraks yang terserap dalam tubuh ini akan disimpan secara komulatif didalam hati, otak, dan testis (buah zakar). Dan pemakaian dalam jumlah banyak akan menyebabkan demam, kebingungan, gangguan pencernaan, kebodohan, pingsan, bahkan kematian. Di dalam kurun waktu yang lama boraks akan terakumulasi di hati sehingga fungsi hati tidak akan berjalan dengan normal. Senyawa racun ini akan beredar lagi didalam darah sehingga ginjal tidak mampu mengekresikannya melalui urin kemudian mengganggu fungsi ginjal bahkan dapat mengakibatkan kerusakan ginjal.

Daya toksitas boraks adalah LD-50 akut 4,5-4,98 $\mathrm{gr} / \mathrm{kg}$ berat badan (tikus). Dalam dosis tinggi, boraks dalam tubuh manusia bisa menyebabkan pusin-pusing, muntah, mencret, kram perut dan lain-lain. Pada anak kecil dan bayi, boraks sebanyak 5-6 gram didalam tubuhnya dapat menyebabkan kematian. Sedangkan kematian pada orang dewasa terjadi jika dosisnya mencapai 10-20 gram atau lebih (Winarno, F.G. 2004).

Salah satu bahan makanan yang bisa dicurigai mangandung boraks adalah ayam potong karena biasanya produsen menggunakan boraks pada ayam potong agar proses penyimpanan menjadi tahan lama, tidak mudah dihinggapi lalat dan dagingnya akan terlihat segar meski disimpan dalam waktu yang lama. Sangat sulit untuk menentukan makanan itu mengandung boraks jika dilihat secara fisik, kecuali jika diperiksa melalui uji laboratorium.

Kekurangan metode Cutton bud adalan ketika Cutton bud diwarnai dengan kunyit, kita tidak bisa mendeteksi konsentrasi kunyit yang kitapakai untuk mewarnai cutton bud sehingga hasil yang kita dapat belum tentu positif atau negatif, dikarenakan juga cara penglihatan setiap orang berbeda-beda.sedangkan kelebihan 
dari metode Cutton bud adalah bahannya mudah didapat,murah dan mudah dibawa kemana-mana.

\section{KESIMPULAN}

Berdasarkan hasil penelitian pada pada 20 sampel paha ayam potong yang dijual pada pasar pa'baeng-baeng Makassar hanya 1 yang positif (+) mengandung borak yaitu sampel dengan kode sampel B sedangkan 19 sampel negatif (-) tidak ditemukan adanya kandungan boraks.

\section{DAFTAR PUSTAKA}

BPOM BH dan H. Sehat duniaku menuju generasi emas yang sehat dan berkualitas [Internet]. 2014 [cited 2014 Apr 4]. Available from: http://www.pom.go.id/new/index.php /view/ pers/225/Sehat-Duniaku-
Menuju-GenerasiEmas---yang-Sehatdan-Berkualitas.html 2.

Bahri, S, 2008. Pangan Beberapa Aspek Keamanan Asal Ternak Diindonesia. Pengembangan inovasi Pertanian. Bandung.

Cahyadi, Wisnu. 2009. Bahan Tambahan Pangan, PT Bumi Askara. Jakarta.

Kemenkes RI. Pedoman keamanan pangan di sekolah dasar. Jakarta: Kemenkes RI; 2011.

Murti, Tridjoko, W. 2014. Pangan, Gizi dan Teknologi Susu. Gadjah Mada University Press.Yogyakarta.

Winarno, F.G. 2004. Kimia Pangan dan Gizi, PT Gramedia Pustaka Utama, Jakarta. 